\title{
AC 2008-2410: CAPTURING STUDENTS FOR MANUFACTURING ENGINEERING - COUNTERING THE REVERSE FUNNEL PIPELINE
}

\section{Danny Bee, University of Wisconsin-Stout}

DANNY BEE is an Assistant Professor of Manufacturing Engineering since 1995, the current program director for the M.S. in Manufacturing Engineering major, a former Program Director for the B.S. in Manufacturing Engineering major at University of Wisconsin-Stout. He earned a B.S. in Mechanical Engineering at University of Wisconsin-Madison and a M.S.in Manufacturing Systems Engineering at the University of Wisconsin-Madison. He currently teaches courses in sustainable engineering, manufacturing technology, manufacturing process science, and system simulation. He has design/manufacturing experience in the aerospace and computer industries. In addition, he worked as a Quality Specialist in the Janesville/Beloit, WI region at Blackhawk Technical College. He is currently a Ph.D. student in mechanical engineering at Michigan Technological University, developing research in the area of sustainable design and development.

\section{Richard Rothaupt, University of Wisconsin-Stout}

RICHARD ROTHAUPT is the Associate Dean of the College of Technology, Engineering and Management and a former Program Director for the B.S. in Manufacturing Engineering major at University of Wisconsin-Stout. He earned a B.S. in Industrial Education at University of Wisconsin-Stout, a M.S.in Vocational Education at the University of Wisconsin-Stout, and a Ph.D. in Vocational Education/Industrial Technology from Colorado State University, Fort Collins. Prior to joining the college administrative team, he instructed courses in computer aided manufacturing as well as the Capstone II system build course within the undergraduate manufacturing engineering major.

\section{Linards Stradins, University of Wisconsin-Stout}

LINARDS STRADINS is an Associate Professor of Manufacturing Engineering since 1996 and the current program director for the B.S. in Manufacturing Engineering major at University of Wisconsin-Stout. He earned a B.S. in Mechanical Engineering at University of Wisconsin-Milwaukee, a M.S.in Mechanical Engineering at the University of Wisconsin-Madison, is ABD in his Ph.D. in Mechanical Engineering at University of Wisconsin-Madison. He currently teaches courses in mechanics of materials, heat transfer, engineering design, fluid mechanics, and the Capstone I systems design. He has prior work experience in the automotive/truck industries and his Ph.D. research focuses on polymers research and computational mechanics. 


\title{
Capturing Students for Manufacturing Engineering - Countering the Reverse Funnel Pipeline
}

\begin{abstract}
This paper will discuss successful techniques for recruiting and retaining manufacturing engineering students and tested methods to debunk the myths and negative perceptions of manufacturing and engineering in the USA. Topics will include: improving the pool of students interested and capable of manufacturing and engineering study, using local media to your advantage, on-campus recruiting techniques, and ideas to improve student retention in engineering. Attention will be paid to methods that University of Wisconsin-Stout has found to be successful in selling the Manufacturing Engineering (ABET-EAC accredited) program to students, parents, and employers. The paper will invite all interested parties to participate in a national dialogue on capturing students for manufacturing engineering careers.
\end{abstract}

\section{Undergraduate Manufacturing Engineering at University of Wisconsin-Stout}

University of Wisconsin-Stout developed the Bachelor of Science in Manufacturing Engineering program during the early 1990s and subsequently began enrolling students into the program in 1994. The first graduating class was in December of 1996, due in part to the fact of early enrollment and advisement of existing and transfer students into courses aligned with the new curriculum prior to its "official" availability. The curriculum development process was intensively industry based and heavily relied upon the Curriculum 2000 project work of the Society of Manufacturing Engineers.

The curriculum is a general approach to manufacturing engineering and does not specifically target any one industry in the content. This general approach has allowed graduates of the program to work in any industry, as evidenced by the wide spectrum of manufacturing employers of the program graduates. Graduates of University of Wisconsin-Stout's manufacturing engineering program can be found in the foods, military aircraft, automotive, plastics, special machine research, medical devices, foundry, building products, and consumer products industries. This "general engineering" approach utilizes many of the other engineering disciplines for instructional topics, i.e., mechanical, industrial, electrical, and materials science as well as a core curriculum in engineering management.

Another aspect of demonstrated success of UW-Stout's manufacturing engineering program is the target market for its graduates. In the part of the state where the institution is located, most manufacturers are of the small to medium size. This requires students to have a broad spectrum of manufacturing knowledge, since these small manufacturers typically have a limited number of manufacturing engineering staff, and these manufacturing engineers are typically dealing with many different issues every day. This small to medium sized target market dictates a general approach to manufacturing engineering. 


\section{UW-Stout's B.S. in Manufacturing Engineering Enrollment}

As the undergraduate program in manufacturing engineering grew from its creation in 1994, the program peaked at 259 students in 1998 . Shortly thereafter, the program began a precipitous decline dropping to a low of 123 students in 2003. This enrollment drop was due to many external factors, i.e. economic slump of 2000 and 2001, persistent negative manufacturing news headlines, and a general perception that manufacturing careers are dirty and not exciting, all of which contribute to a lack of awareness of the exciting career possibilities for manufacturing engineers. University of Wisconsin-Stout began an aggressive campaign of recruiting directly for the engineering and technology based programs in 2002. Through a series of integrated activities, the program has been brought back to 183 students. Figure 1 depicts the enrollment data for the manufacturing engineering program. It clearly shows a precipitous decline after the initial startup spike and highlights a period of growth as a result of the recruiting strategies used. Since there has been a steady enrollment increase since 2004, it is unclear whether a true steadystate enrollment has been found. At the time of writing, the Fall 2007 applications are exceeding any prior year application rates. Historically, the manufacturing engineering program has a accepted application fall show rate of roughly 70 percent, thus indicating Stout's program is a first choice program for students. This show rate is significantly higher than most majors on campus.

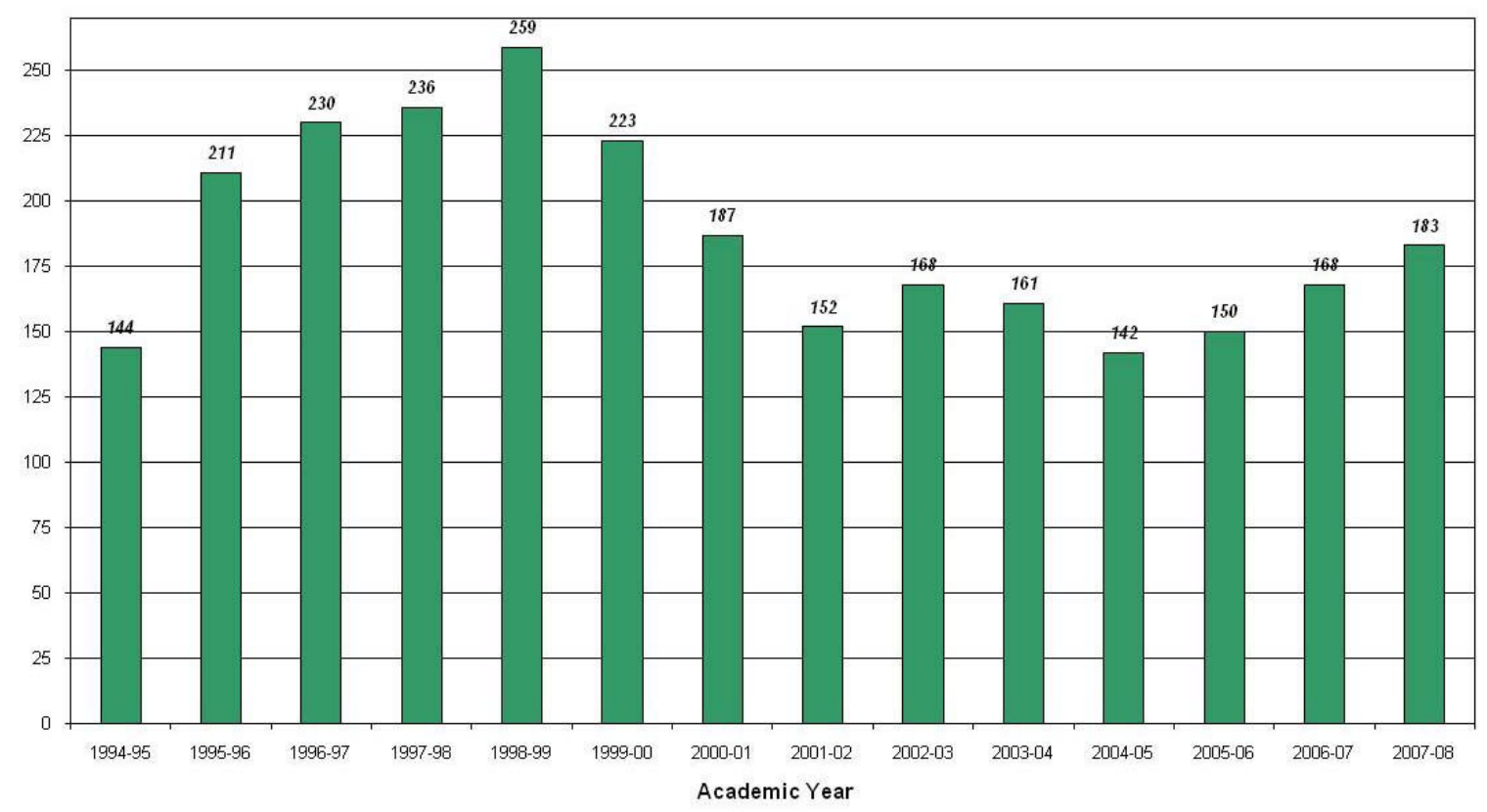

Figure 1. UW-Stout B.S. in Manufacturing Engineering enrollment. 


\section{Recruiting and Shaping Manufacturing Engineers}

At the risk of stereotyping, the education world often practices a reverse funnel to recruiting, shaping, and providing career opportunities to potential engineers. This reverse funnel might look like the figure depicted in Figure 2. Many engineering schools have what could be called a "field of dreams" approach to recruiting. These schools believe that they have an excellent reputation for engineering and since they have built these great engineering programs, the students will find them and come to their school. There is also a very troublesome approach to engineering education once the students do arrive to them. The opportunities and

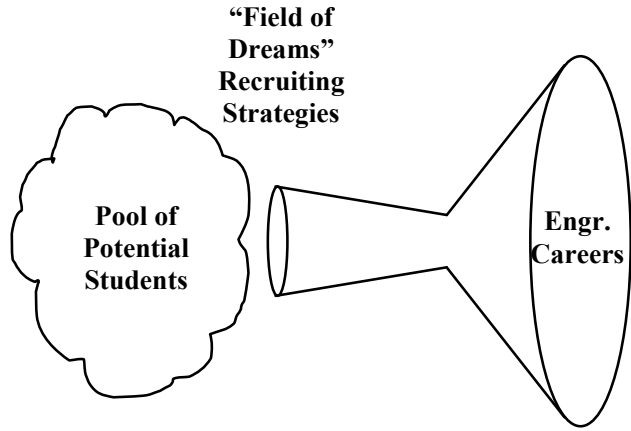

Figure 2. Reverse funnel recruiting. educational experiences are typically designed to winnow down the students to those select few who have made the grades and survived through the curriculum. Support systems and external opportunities often do not nurture the student into their selected career interests. The students are filtered out as not successful enough.

When adopted by a manufacturing engineering program, this reverse funnel to recruiting and shaping the manufacturing engineers only works to the detriment of the program. As shown by Bee and Meyer, there is a strong need for manufacturing engineers and an urgent call for promotion of manufacturing careers. ${ }^{1}$ When the career opportunities are so high and there are so few students already, the manufacturing engineering programs must do more to attract students. Programs will wither away and disappear, as evidenced by recent trends in programs dropping ABET accredited manufacturing engineering programs. ${ }^{2}$ As shown in Figure 3, the manufacturing engineering career potential is enormous. However, if the manufacturing engineering curriculum still practices the winnowing approach to thinning the number of students in the program, the program will still be taking a small number of incoming students and further reducing them to have an even smaller number of students available for employment as manufacturing engineers.

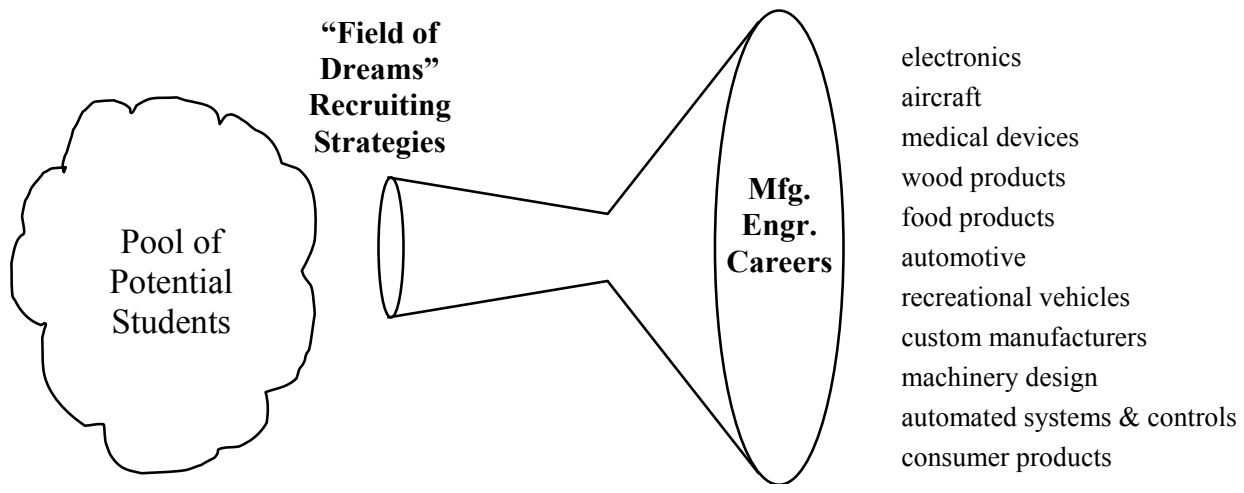

Figure 3. Career opportunities abound for few students.

University of Wisconsin-Stout practices a comprehensive approach to recruiting and supporting students in the manufacturing engineering program. Figure 4 illustrates the approach taken. Of 
particular note is the fact that there is an extensive array of programs and activities that open up the flow of students from our potential pool of students. These programs either promote the manufacturing engineering careers directly or indirectly through programs promoting engineering in general. University of Wisconsin-Stout also has numerous support strategies that directly involve the manufacturing engineering students in internal and external career opportunities, develop career ready graduates, and practice a "hands-on" approach to real industry projects.

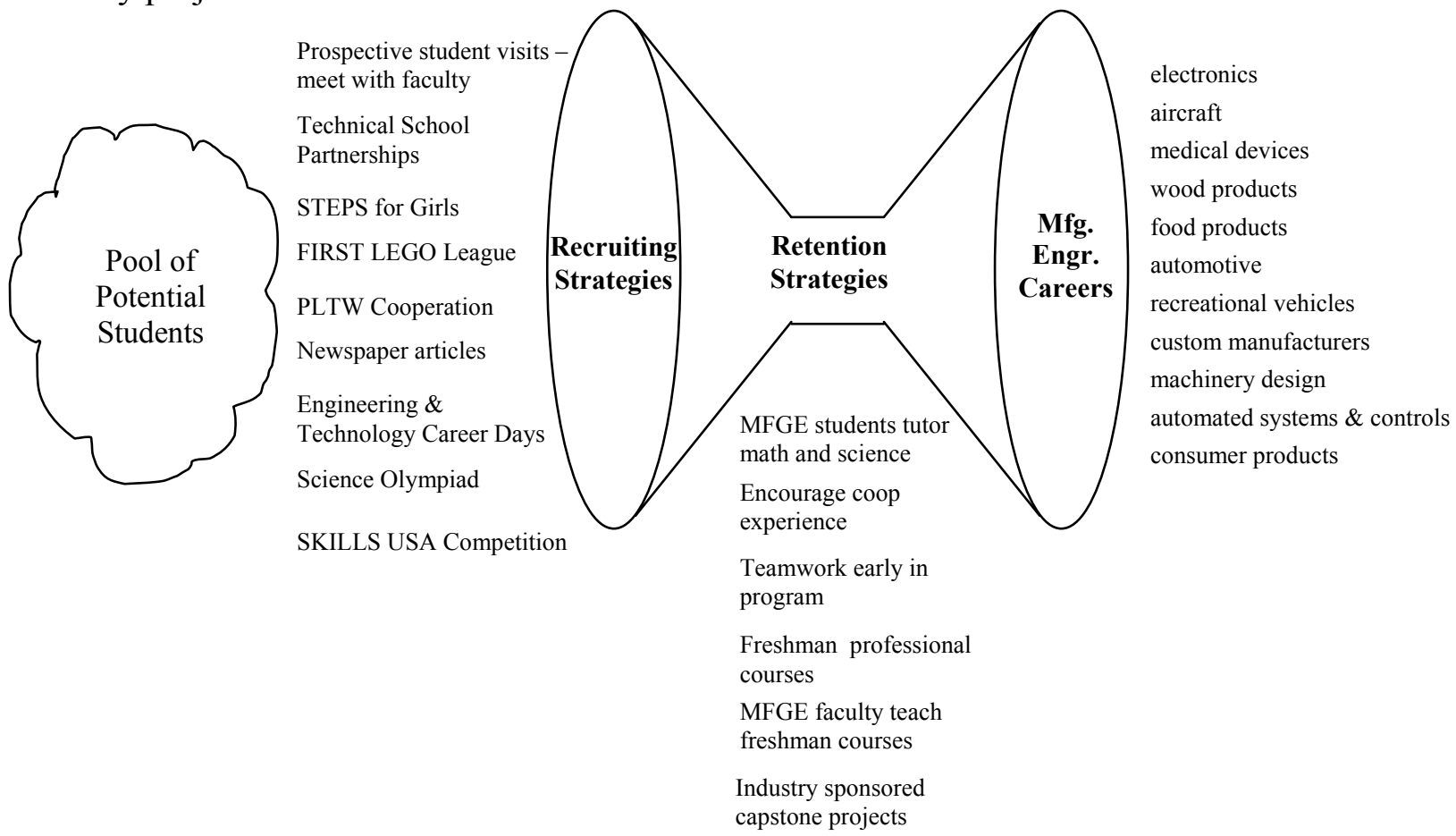

Figure 4. UW-Stout's comprehensive recruiting and retention strategies.

\section{Marketing Strategies}

When listed together, the programs that University of Wisconsin-Stout either directly runs or supports looks like an amazing array of direct manufacturing engineering programs to ones that are more generically recruiting engineers at very early ages. Programs like STEPS2, FIRST LEGO League, Skills USA, and Science Olympiad, target students as young as elementary school to interest them in engineering and help them realize they can be involved in a fun and exciting career such as engineering and most importantly, help them realize they personally can succeed in this career pursuits. For example, FIRST LEGO League (FLL) promotes a robotic design challenge along with a related research project. Students gain valuable experience having fun designing and building a LEGO robot, but they also research a current and relevant engineering problem and present that to a panel of judges during a sporting event style competition. University of Wisconsin-Stout currently hosts a regional tournament in the state of Wisconsin and is putting plans in place to be the primary host of the State FLL tournament. Another example would be the Science, Technology, and Engineering Preview Summer Camp for Girls (STEP for Girls). ${ }^{3}$ This seventh grade (girls are entering seventh grade) experience gives young females an opportunity to experience engineering and manufacturing first hand in a 
non competitive environment and helps them build the confidence it takes to successfully maintain involvement in the prerequisite math and science curricula in middle and high school. Of significance with this program is its effect on girls being nearly 10 times more likely to pursue an engineering career as their peers who did not go through this program.

One key high school recruiting activity developed by our College of Technology, Engineering and Management are the Engineering and Technology Career Days. Two of these are hosted on campus throughout the academic year, with each session attracting over 200 students to campus. During the fall semester, a junior/senior career day is hosted, and during the spring semester, a freshman/sophomore career day is hosted. Students select three program breakout sessions where they participate in hands-on lab activities related to the program being visited. A lunch is also provided with a panel of recent program alumni, coop, or seniors discussing the different engineering and technology programs. This has become a staple engineering and technology recruiting tool.

A final activity found to be of utmost importance for recruiting students at UW-Stout are the face-to-face meetings with prospective students and their parents. A private school image is projected through these visits to this state funded public university. When contacted by the Admissions office, the program director, or another available faculty, will meet for one hour with the prospective student visitors. The program will be briefly explained and then a tour demonstrates the hands-on approach to manufacturing engineering education. Usually, the tour highlights a classroom lab activity in progress so the students can understand what is meant by "hands-on" engineering instruction. A key aspect of this meeting is the sharing of a consistent and appealing package of information about the engineering program that faculty can use and the students can refer to after the campus visit.

University of Wisconsin-Stout is also a leader in the State of Wisconsin in Technical School articulations. Numerous articulation agreements exist with these technical schools and other preengineering offerings around the region. University of Wisconsin-Stout is a training site for students involved in teaching Project Lead the Way (PLTW) within middle and high school science and technology education programs. In addition, on alternate years, University of Wisconsin-Stout is a host site for the statewide Science Olympiad which annually draws over 500 students to the competition. In addition to all of these above listed programs, University of Wisconsin-Stout never hesitates to ensure newspaper and local TV outlets are covering stories about events in the manufacturing engineering program as well as any of the other outreach programs listed here.

\section{Retention Strategies}

University of Wisconsin-Stout builds on its rich history of hands-on lab experiences and a strong relationship with the industry served by its program in the retention strategies practiced while the students are attending the program. UW-Stout's manufacturing engineering program has averaged 58 percent first year retention during the time period 2000 to 2005 . It must be noted that freshmen are admitted directly into the manufacturing engineering program at UW-Stout. This statistic may not be directly comparable to other engineering schools since most schools admit freshmen into the engineering majors only after completion of a pre-engineering program. 
To accommodate this fact, retention statistics are presented here for the students that are retained from the freshmen to sophomore year. For those that were retained the sophomore to junior retention statistic shows that between 61 and 91 percent of these students stay with the major. Figure 5 shows the comparison of the one year (freshmen to sophomore) and second year (sophomore to junior) retention statistics.

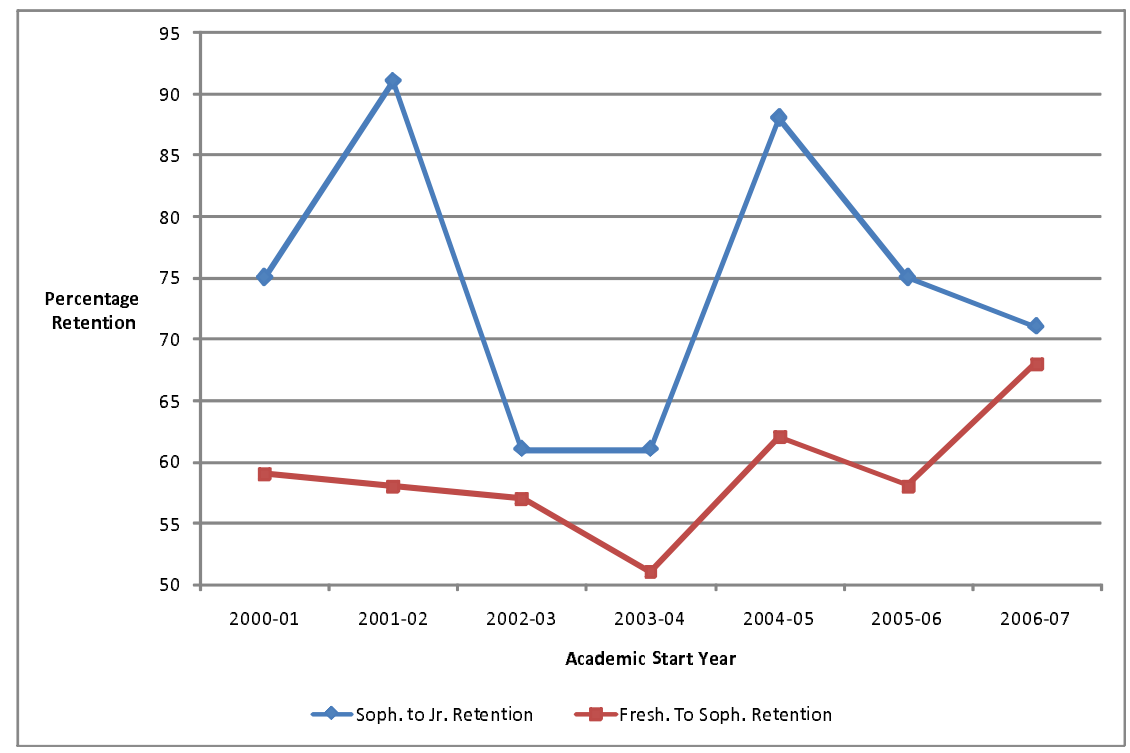

Figure 5. UW-Stout B.S. in MFGE retention statistics.

During their first semester, students are required to take a three credit Introduction to Engineering Materials course. This course is required in the program and instructed by manufacturing engineering faculty. This gives students an experience beyond the general mathematics, science and liberal studies general education and maintains their interest for staying with the major. The Introduction to Engineering Materials course is not a one credit "general engineering" course, but it has content used later in the curriculum within the context of the hands-on lab activities. Second, the manufacturing engineering students work on project teams throughout the program, closely resembling a real world engineering career. Third, the students are strongly encouraged to pursue and obtain a direct manufacturing engineering cooperative work experience. Minimally, students will do this as a summer internship, and maximally they will do this as a six month cooperative experience. Students obviously gain a direct working knowledge of manufacturing engineering and often end up working for the company they perform this cooperative experience with. Finally, the capstone project experiences are usually industry sponsored projects. This serves two purposes. The projects are current, relevant and real life examples of problems faced by manufacturing engineers. The projects are also a recruiting tool for employers as the students begin to understand the industry the project is coming from. This has worked well for a food manufacturer that has very exciting manufacturing engineering careers but had difficulty recruiting students to their industry.

By far, the approach to engineering education practiced by all faculty at UW-Stout is a key retention tool. Typically, all faculty instructing courses within the major have significant industry experience. This also translates directly into hands-on engineering education. The education is hands-on since the students use the manufacturing process equipment they will 
experience in their future careers. Engineering processes and material theory is supported by the lab applications and utilization of the equipment. This produces a career-ready graduate that has extensive familiarity with equipment use and in-depth process understanding. To understand the teaching methodology practiced at Stout, see the 2001 paper presented by Bee. ${ }^{4}$ Student comments, from the Senior Exit Survey, on how important this engineering education approach is. A key exit survey statistic is the rating from students for their inclination to recommend the program to their peers. A positive trend is shown in this data indicating student satisfaction with the program and a willingness to recommend the program to a close friend or relative.

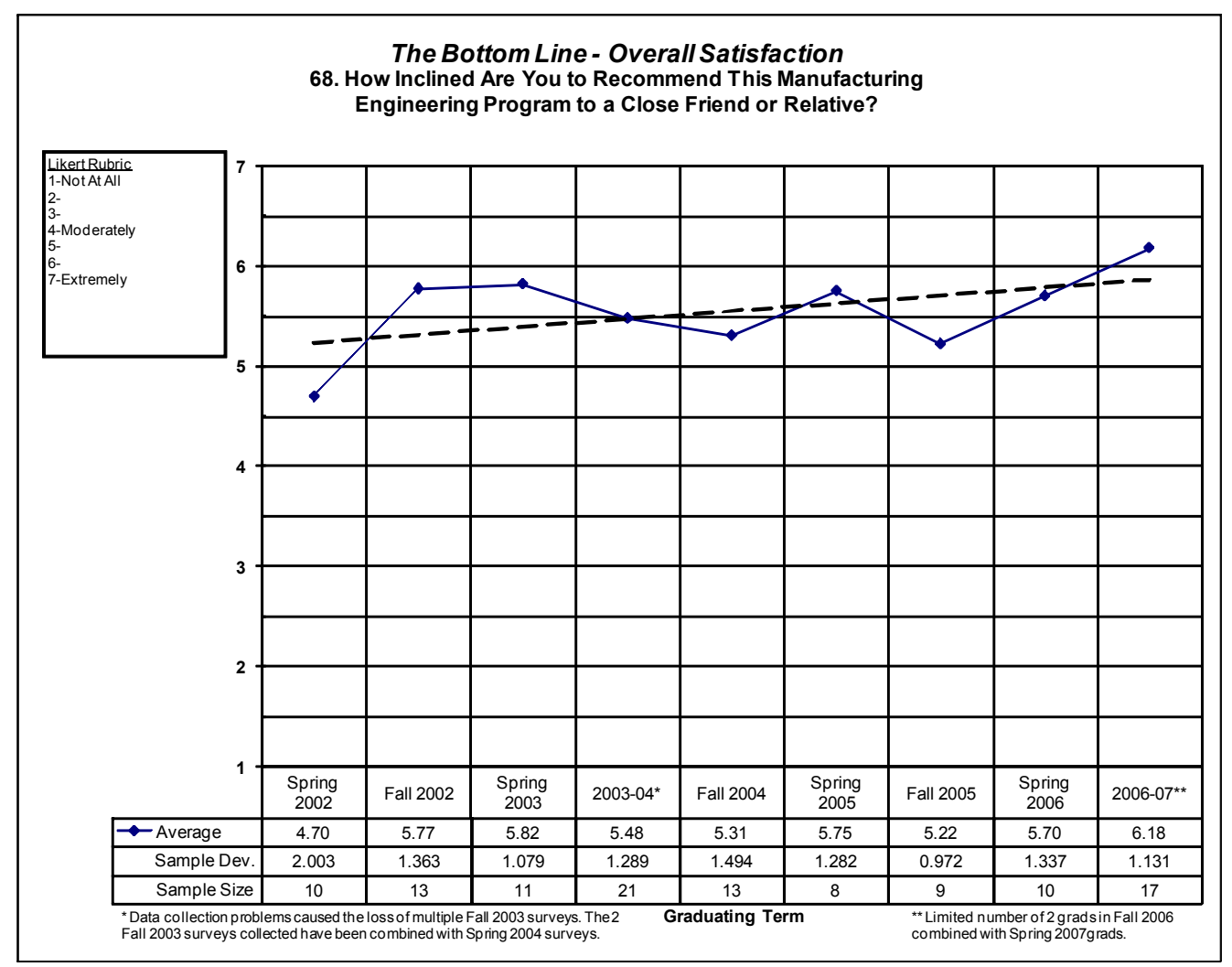

Figure 6. Senior exit survey result recommending Stout's B.S. in MFGE program.

In addition to the strategies listed above, many manufacturing engineers are typically tutors hired by the mathematics and science departments. This gives the students an opportunity to work with other students as they hone these math and science skills.

\section{Career Opportunities}

University of Wisconsin-Stout has an extensive list of employers of graduates of the program. As shown in the list of manufacturing career opportunities in Table 1, the UW-Stout general approach to manufacturing engineering education allows students to pursue employment in any industry they desire. 


\begin{tabular}{lll}
\multicolumn{1}{c}{ Table 1. Partial List of UW-Stout Manufacturing Engineering Employers } \\
3M & Hormel Foods & Parker Hannifin \\
Ace Precision & Hurd Millworks & Pemstar Inc. \\
Andersen Window & HUSCO International & Phillips Plastics Corporation \\
& Hutchinson Technology, & \\
Bradley Corporation & Inc. & Plexus Corp. \\
CL\&D Graphics & IBM & Polaris \\
Classic Manufacturing & International Paper, Inc. & Prent Corp. \\
Clopay Building Products & John Deere & Quality Tool \\
Concept Engineering & KI & Remmele Engineering \\
Cummins Power Generation & & \\
(Onan) & Kohler Company & Rockwell Automation \\
Curt Manufacturing & Kolbe-Kolbe Millworks & Schaeffer Engineering \\
Dayco & Kurt Mfg. & Scientific Molding Corp. \\
Donaldson Company Inc. & Laser Magic, Inc. & Semco Windows and Doors \\
Donatelle Plastics Inc. & LasX Industries & SSI Technologies, Inc. \\
Eaton & Lockheed-Martin & St. Jude Medical \\
Elkay Manufacturing Company & Lynch Machinery & Stratasys \\
Emerson Electric & Marquip Inc. & Swiss Technologies \\
Fastenal Company & May Steel LLC & Tool-O-Matic \\
Federal Mogul & Mayo Clinic & Trane Co. \\
Flambeau Plastics & McNeilus Steel Inc. & Trostel \\
& & TRW Thermo King, Ingersoll- \\
Flexmedics Corporation & McQuay International & Rand \\
Frito-Lay., Inc. & Medallion Cabinetry & BAE Systems (United Defense) \\
Gilman Engineering & Mercury Marine & United Gear \& Assembly \\
Goodrich Aerospace & Metallics Inc. & Uponor-Wirsbo \\
GPI Corp. & MRG Tool and Die, Inc. & W.L. Gore \\
Greenheck & Nestle & Waukesha Bearing \\
Harley-Davidson & OEM Fabricators Inc. & Waupaca Foundry \\
Hearth \& Home Technologies & Oildyne & Wausau Metals \\
Hemerlus & Oshkosh Truck & Whirlpool Corporation \\
Honeywell International & Owatonna Tool Corp. & \\
& & \\
& &
\end{tabular}

The challenging part, from a program and career placement services point of view, is to help the students understand the vast array of potential employers, industries, and career paths available to them. This is done through a very active Career Services office as well as from faculty advisement with the students.

\section{Conclusions}

The University of Wisconsin-Stout has a vibrant and growing bachelor of science in manufacturing engineering major. Improving the pool of students interested and capable of manufacturing and engineering study, using local media to your advantage, on-campus recruiting techniques, and ideas to improve student retention in engineering have all been discussed. We invite all manufacturing engineering programs to enter a national dialogue on manufacturing engineering education. All parties involved must be active participants in promoting manufacturing engineering, manufacturing technology, and engineering education for our continued success in manufacturing. 


\section{References}

1. Bee, D. and Meyer, B., 2007, Opportunities and Challenges for Manufacturing Engineering, 2007 ASEE Annual Conference Proceedings, American Society for Engineering Education, Honolulu, HI.

2. Jack, H., 2005, State of Manufacturing Engineering Education, Technical Paper TP05PUB209, Society of Manufacturing Engineers, Dearborn, MI.

3. Bee, D., Puck, B., and Heimdahl, P., 2007, Ten Years of STEPS Success: Significant Impact in Attracting Girls to Science, Technology, and Engineering Careers, 2007 ASEE Annual Conference Proceedings, American Society for Engineering Education, Honolulu, HI.

4. Bee, D., 2001, Back to the Future Manufacturing Engineering at Stout, 2001 ASEE Annual Conference Proceedings, American Society for Engineering Education, Montreal, Quebec, Canada. 